Original Article

\title{
HEALTH SEEKING BEHAVIOR OF RURAL ADULTS
}

\section{Rose Ann Dominic ${ }^{1}$, Shashidhara Y.N. ${ }^{2} \&$ Malathi G. Nayak ${ }^{3}$}

${ }^{1} \mathrm{M}$ Sc. Nursing, ${ }^{2}$ Associate Professor, ${ }^{3}$ Assistant Professor, Department of Community Health Nursing, Manipal College of Nursing, Manipal University

Correspondence :

Malathi G. Nayak

Assistant Professor (Sr. Scale), Department of Community Health Nursing Manipal College of Nursing, Manipal University, M anipal, Karnataka, India.

E-mail : malathinayak@yahoo.co.in, malathidgn67@gmail.com, malathi.nayak@manipal.edu Mobile : +919449586431

\section{Abstract :}

Background : The knowledge of health seeking behavior is pivotal for prevention, treatment, management of disease and promotion of health. Proper understanding of those health seeking behaviors could reduce delay to diagnosis, improve treatment compliance and improve health promotion strategies in a variety of contexts.

Objectives : to assess the health seeking behavior among rural adults towards private and public health care facilities in case of selected health problems, to find the association between health seeking behavior and selected demographic variables.

Materials and Methods : A descriptive survey was done among 260 rural adults by using self administered rating scale questionnaire. Descriptive and inferential statistics were used for the analysis.

Results : Among the 260 samples $28.8 \%$ were having positive health seeking behavior towards government health care facilities. M ajority of the sample i.e. $71.2 \%$ were having negative health seeking behavior towards government health care facilities. There is a significant association between health seeking behavior and demographic variables such as age, education and family income.

Conclusion : M ajority of the sample prefers to use private health care facilities during the period of their illness. Awareness to be given to the community people regarding availability of public health care facilities.

Keywords : Health seeking behavior, selected health problems, rural adult

\section{Introduction:}

Indian population mainly lies in rural areas. According to 2011 census $69 \%$ of Indian population comprises of rural population. In Karnataka the people living in rural area is more $(66 \%)$ than that of urban area ${ }^{1}$. Since people of India are mainly rural and less educated they have misconceptions about the available health care services and medicines. An awareness of the health seeking behavior is paramount in the treatment of patients. Health seeking behavior in terms of illness behavior refers to those activities undertaken by individuals in response to symptom experience. ${ }^{2}$

\begin{tabular}{|c|}
\hline Access this article online \\
\hline Quick Response Code \\
\hline
\end{tabular}

The knowledge of health seeking behavior is pivotal for prevention, treatment, management of disease and promotion of health. It is the perceptions of the rural consumers of health care services that make the community health programmes and initiatives successful or failure. The findings of the study will benefit in implementation and execution of community health care programmes and to promote utilization of services provided through public health infrastructure. It is vital that primarily the perceptions, attitudes and expectations of the community, who is the actual consumer, be outlined and then accordingly further activities are planned and implemented.

\section{Problem statement :}

A study to assess the health seeking behavior of rural adults towards private and public health care facilities in selected villages of Udupi district.

\section{Purpose of the study:}

The purpose of the study is to assess the health promotion activities of rural adults through assessing their health seeking behavior regarding quality of health care services. Proper understanding of health seeking behavior could 
reduce delay to diagnosis, improve treatment compliance and improve health promotion strategies.

Objectives: The objectives of the study were

I to assess the health seeking behavior among rural adults towards private and public health care facilities in case of selected health problems

I to find the association between health seeking behavior and selected demographic variables.

\section{Hypothesis:}

There will be a significant association between health seeking behavior and selected variables

\section{Assumptions:}

I Age, gender, religion, education, occupation, monthly income of the family can play a key role in people's health seeking behavior regarding the quality of health care services

I Lack of good information regarding various health care services can influence health seeking behavior

I Past experiences with disease and behavior of health professional can influence health seeking behavior regarding the quality of health care services.

\section{Variables:}

Primary outcome variables: Health seeking behavior

Extraneous variables: age, gender, religion, occupation, monthly income of the family, type of family and house hold size.

\section{Materials and Methods:}

A community based cross sectional descriptive study was carried out in order to explore the health seeking behavior of rural adults towards private and government health care facilities in case of selected health problems. A non probability purposive sampling was used to select 260 adults aged between 20-60yrs who are willing to participate in the study were included in the study.

To meet the objectives of the study, the following tools were used.

1 Tool 1: Demographic Proforma

I Tool 2: 3 point rating scale to assess the health seeking behavior towards government and private health facilities.

The demographic proforma consisted of 9 items seeking information on background data like age, gender, religion, education, occupation, monthly income of family, type of family, house hold size and health care preference. The tool 2 comprised of total 19 items. These items covered different areas including general health problems, chronic health problems, children's health problems, reproductive health category, gynecological problems, mental health problems and old age problems. Each item had two parts:Government and private. The sample were asked to mark their response in both the parts i.e. Government and private. The items were scored using a 3 point rating scale: (1) always, (2) sometimes, (3) never, and it was scored as 2, 1 and 0 respectively. The maximum score was 38 and the minimum was 0 . The total score is categorized as negative health seeking behavior (0-19) and positive health seeking behavior (20-38). The reliability of the tool was calculated by Crohn Bach's alpha method and it was found to be 0.83 for health seeking behavior towards government and 0.91 for private health care facilities. The tool was found to be reliable. The pilot study was conducted after obtaining administrative permission and written consent from 20 participants, who were residing in Athrady. The main study data was collected from 260 adults and data was analyzed by using SPSS version16 statistical package.

\section{Results:}

M ajority of the samples belongs to the age group of 31-40 years (43.5\%). $58.8 \%$ of them were female. $76.5 \%$ of samples belongs to Hindu religion. Majority of the sample were having higher secondary education (34.6\%). M ost of the sample were private employed i.e. $36.9 \%$ and $42.7 \%$ were unemployed. Majority of the families (41.2\%) were having a monthly income between Rupees 10001-25000. $52.7 \%$ subjects belongs to nuclear families and $61.9 \%$ families comprised of 1-5 members (Table 1).

Among the 260 samples $28.8 \%$ were having positive health seeking behavior towards government health care facilities. Majority of the sample i.e. $71.2 \%$ were having 
negative health seeking behavior towards government health care facilities. They visit the government health facilities very rarely. In case of private health care facilities majority of the rural adults (86.2\%) were having positive health seeking behavior towards it while only $13.8 \%$ of the sample were having negative health seeking behavior towards private health care facilities (Fig 1). The mean score of health seeking behavior is higher for private health care facilities than government health care facilities (Table 2). Therefore it is revealed that majority of the samples were utilizing the private health care facilities during their period of health problems.

The data presented in Figure 2 shows, the area wise health seeking behavior towards government health care facilities. For general health problems, majority of the sample never utilize the government health care facilities. $41.92 \%$ sample wished to go always to government health facilities for seeking care for chronic health problems. In case of children's health problems, majority of the sample never wanted to visit government health care facilities. But when it comes to antenatal and delivery services $59.62 \%$ sample wanted to go to government health care facilities always. For gynecological health problems majority of the sample never wanted to go to government health care facilities. In case of mental health problems and old age related health problems, majority of the sample wished to go always to the government health care facilities.

The data depicted in Figure 3 shows, the area wise health seeking behavior towards private health care facilities. For general health problems, majority of the samples visit sometimes only the private health care facilities. $54.81 \%$ sample wished to go always to private health care facilities for chronic health problems. For children's health problems, majority of the sample wanted to visit always the private health care facilities. In case of antenatal and delivery services $56.54 \%$ sample wanted to go to private health care facilities always. For gynecological health problems majority of the sample wished to go always to the private health care facilities. In case of mental health problems and old age related health problems, majority of the sample wanted to go sometimes only to the private health care facilities.

There was significant association between health seeking behavior towards government health facilities and age $\left(x^{2}=45.12 ; p<001\right)$, gender $\left(\chi^{2}=5.12 ; p=027\right)$, education $\left(x^{2}=43.23 ; p<001\right)$, occupation $\left(x^{2}=28.51 ; p<001\right)$, family monthly income $\left(\chi^{2}=10.82 ; p=012\right)$, type of family $\left(\chi^{2}=8.32\right.$; $p=004)$ and house hold size $\left(\chi^{2}=12.4 ; p=002\right)$. Thus the null hypothesis was rejected and research hypothesis was accepted with regard to age, gender, education, occupation, family monthly income, type of family and house hold size (Table 3). In case of private health facilities significant association was found between health seeking behavior and age $\left(\chi^{2}=17.53 ; p<001\right)$, education $\left(\chi^{2}=36.76\right.$; $p<001)$, family monthly income $\left(x^{2}=9.01 ; p=028\right)$ and type of family $\left(x^{2}=6.23 ; p=018\right)$. Thus the null hypothesis was rejected and research hypothesis was accepted with regard to age, education, family monthly income, and type of family (Table 4).

\section{Discussion :}

The present study found that majority of the sample prefer to go to private health care sectors during the period of illness. According to the 2005-06 National Family Health Survey (NFHS) and District-Level Household Survey (DLHS) data, an average of 15 percent of the population that seeks healthcare services in Uttar Pradesh (UP) accesses government health facilities, while 85 percent opt from private providers. This finding supports the present study.

The present study found that majority of the rural adults utilizing private health care facilities during their illness period and this study supports and gives reason why the people use more private health care facilities, a study was conducted by P Singh, Shiv D Gupta to assess the health seeking behavior and health care services in Rajastan. In their study it was found that the problems being faced by the people while utilizing government health care services were inaccessibility due to lack of transportation, unsympathetic attitude of the staff dispensing the health services, and shortage or non-availability of medicines locally4. 
Figure 1: Health seeking behavior among rural adults towards private and government health facilities $(n=260)$

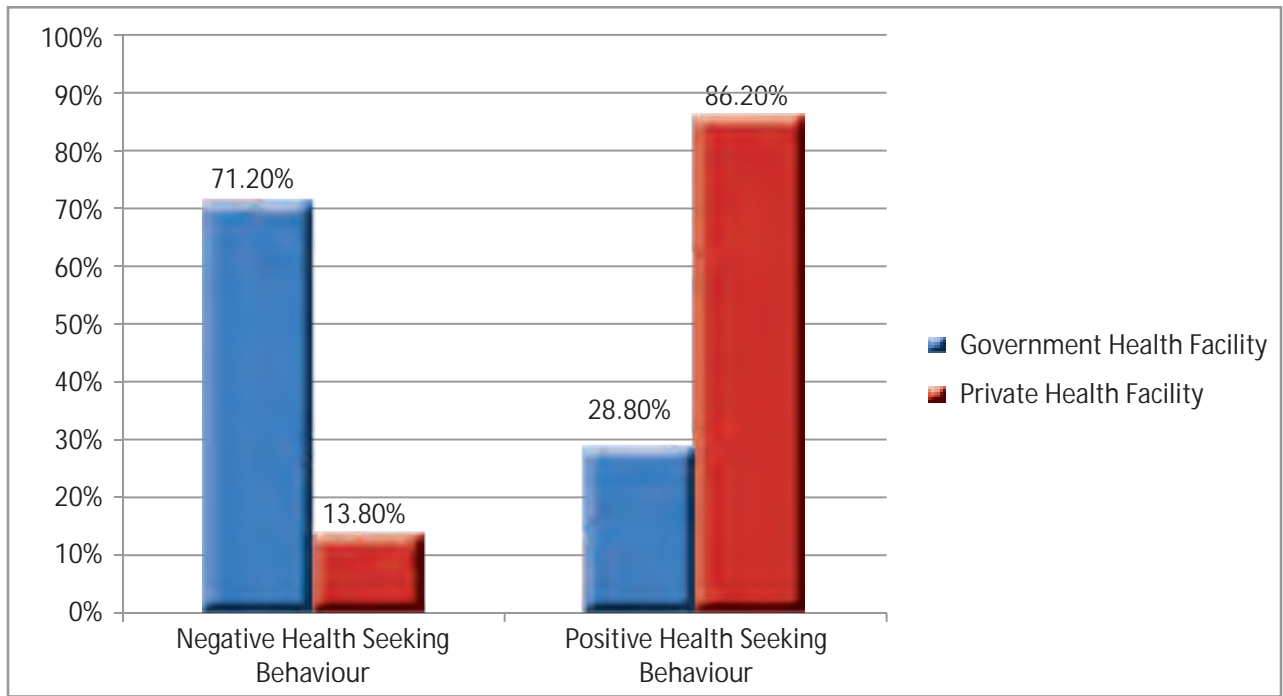

Figure 2: Area wise health seeking behavior towards Government health care facilities

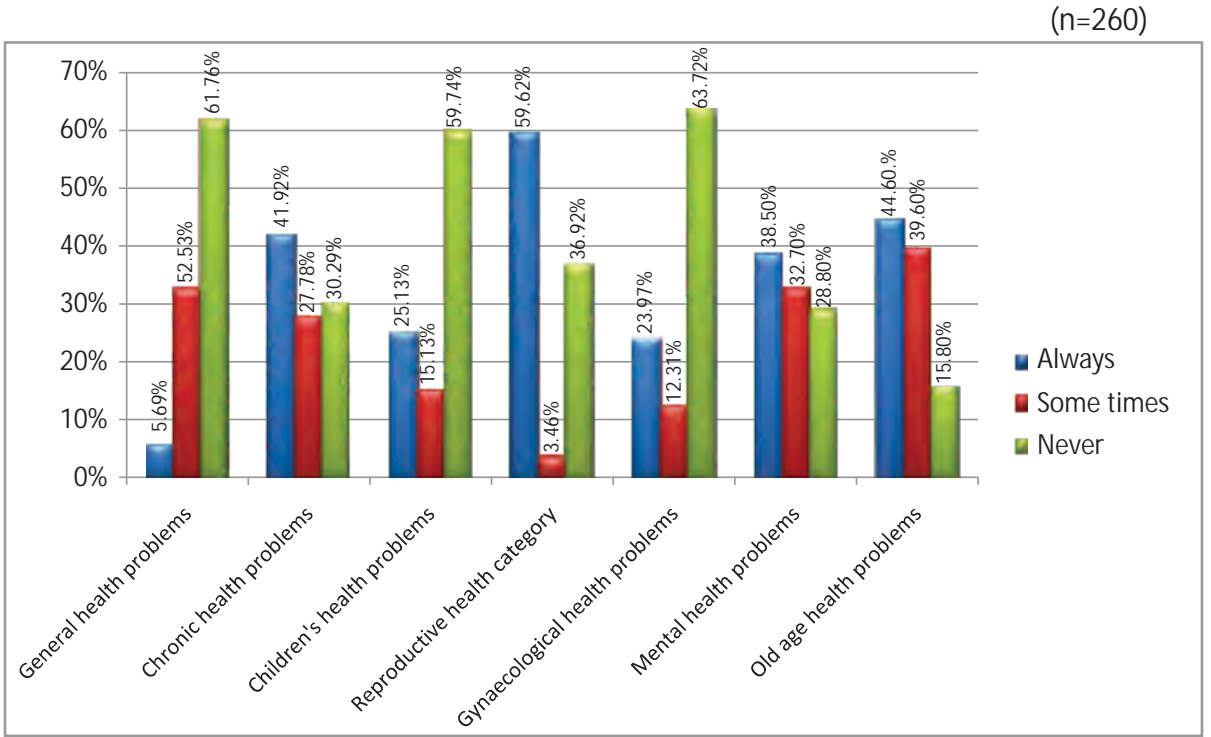

Figure 3: Area wise health seeking behavior towards private health care facilities

$(n=260)$

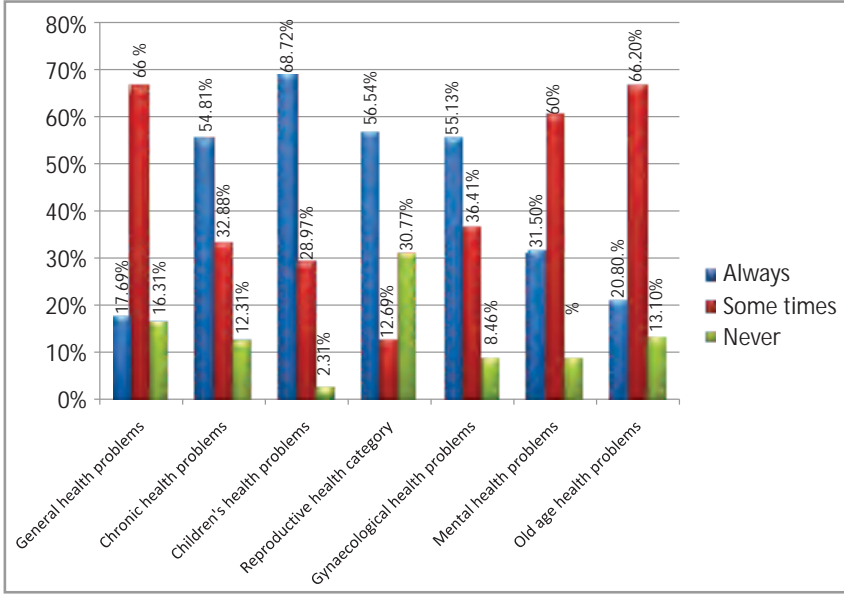


In the present study there was a significant association between health seeking behavior towards private health care facilities and age, education, family monthly income. This is supported by a study conducted by Muhammad Umair M ushtaq, Sibgha Gull, M ushtaq Ahmad Shad, Javed Akram in Pakistan. In their study it was found that use of the private hospitals was associated with better education $(P=0.002)$ and higher income $(P \measuredangle 0.001)^{5}$.

Health seeking behaviour of people is dependent on the perception of people regarding the quality of health care services in health centers. The perception of the people has

Table 1: Frequency and percentage distribution of demographic characteristics of study sample

$(n=260)$

\begin{tabular}{cccc}
\hline Sl. No. & Sample characteristics & $\mathbf{f}$ & $\%$ \\
\hline 1. & Age in years & & \\
$20-30$ & 42 & 16.2 \\
$31-40$ & 113 & 43.5 \\
$41-50$ & 71 & 27.3 \\
$51-60$ & 34 & 13.1
\end{tabular}

2. Gender

$\begin{array}{lll}\text { Male } & 107 & 41.2 \\ \text { Female } & 153 & 58.8\end{array}$

3. Religion

Hindu

Christian

199

Muslim

15

76.5

5.8

4. Education

$46 \quad 17.7$

Primary

61

23.5

Secondary

55

Higher secondary

21.2

Graduate

34.6

Post graduate and above $\quad 14$

5. Occupation

$\begin{array}{lcc}\text { Unemployed } & 111 & 42.7 \\ \text { Cooli worker } & 35 & 13.5 \\ \text { Government employee } & 18 & 6.9 \\ \text { Private job } & 96 & 36.9\end{array}$

6. Monthly income of family in Rupees

$<5000$

30

5000-10000

91

10001-25000

107

$>25000$

32

11.5

35

41.2

12.3

7. Type of family

Nuclear

Joint

137

52.7

123

47.3

8. House hold size

1-5

6-10

161

$>10$

$18 \quad 6.9$

Table 2: Mean and standard deviation of health seeking behavior score

$(n=260)$

\begin{tabular}{lccc}
\hline $\begin{array}{l}\text { Health seeking } \\
\text { behaviour }\end{array}$ & $\begin{array}{c}\text { Maximum } \\
\text { possible score }\end{array}$ & Mean & $\begin{array}{c}\text { Standard } \\
\text { deviation }\end{array}$ \\
\hline $\begin{array}{l}\text { Government Health } \\
\text { facilities }\end{array}$ & 38 & 15.27 & 5.818 \\
\begin{tabular}{l} 
Private Health facilities \\
\hline
\end{tabular} & 38 & 24.98 & 6.027 \\
\hline
\end{tabular}

Table 3: Association between health seeking behaviour towards government health facilities and demographic variables

Sample Health seeking $\chi^{2}$ value df P value

characteristics behavior category

$\begin{array}{lll} & f & f\end{array}$

20-30

$31-40$

$41-50$

51-60

2. Gender

Male

Female

3. Religion

Hindu

Christian

Muslim

4. Education

Primary

Secondary

Higher -secondary

Graduate

Post graduate

and above

5. Occupation

Unemployed

Cooli worker

Government

employee

Private job

6. M onthly income of family in Rupees

$\begin{array}{lcc}<5000 & 16 & 14 \\ 5000-10000 & 59 & 32 \\ 10001-25000 & 84 & 23 \\ >25000 & 26 & 6 \\ \text { ype of family } & & \end{array}$

\section{Type of family}

Nuclear

Joint

\section{House hold size}

1-5

6-10

$>10$

*Significant $(n=260)$

Negative Positive

$45.108 \quad 3 \quad .001 *$

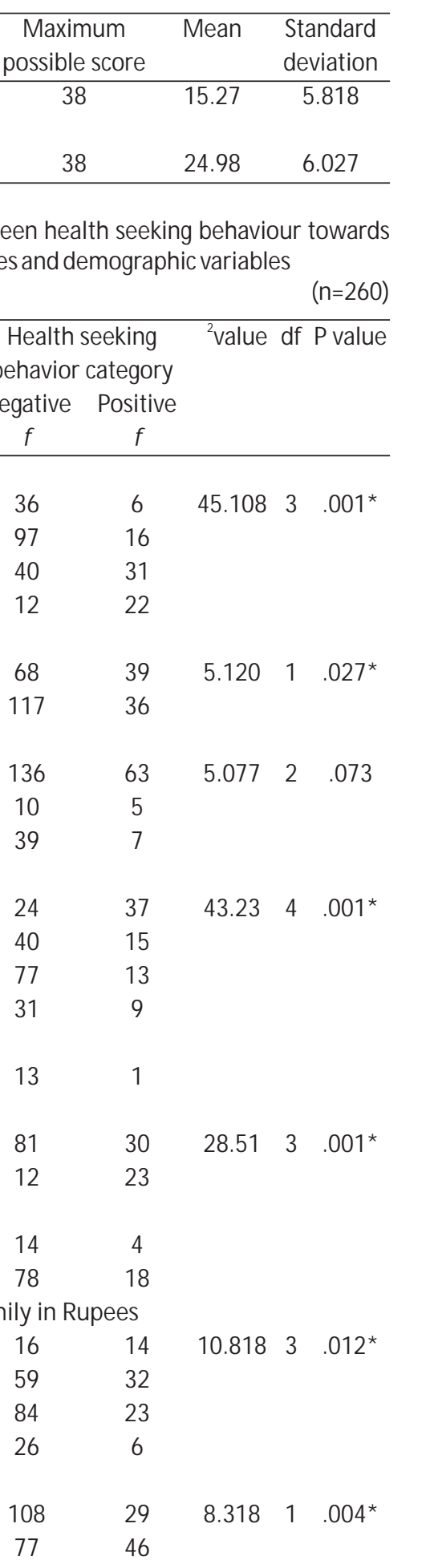

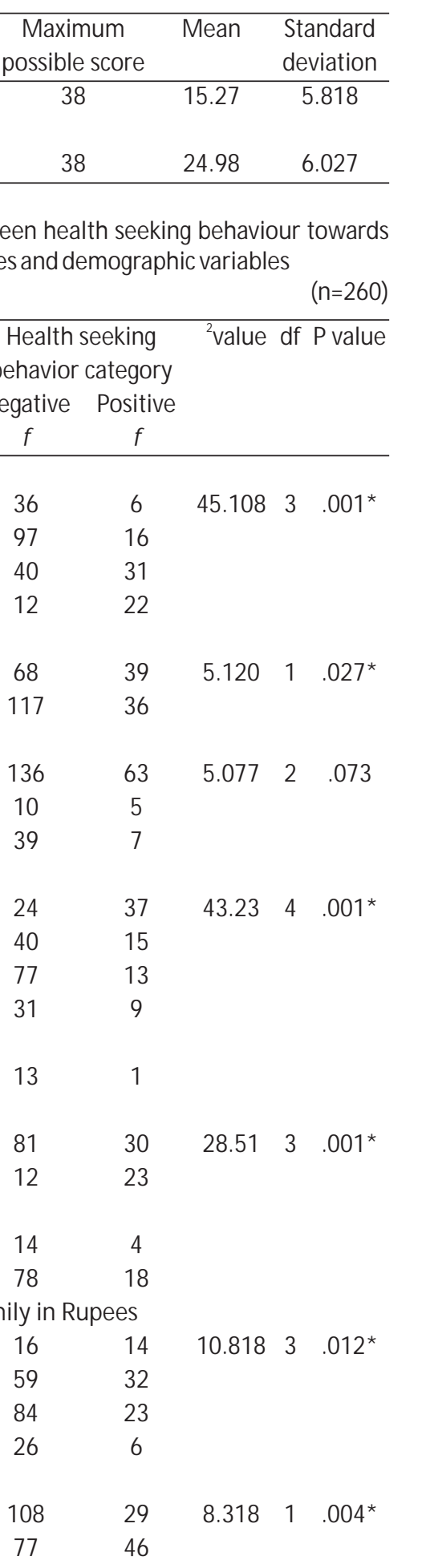

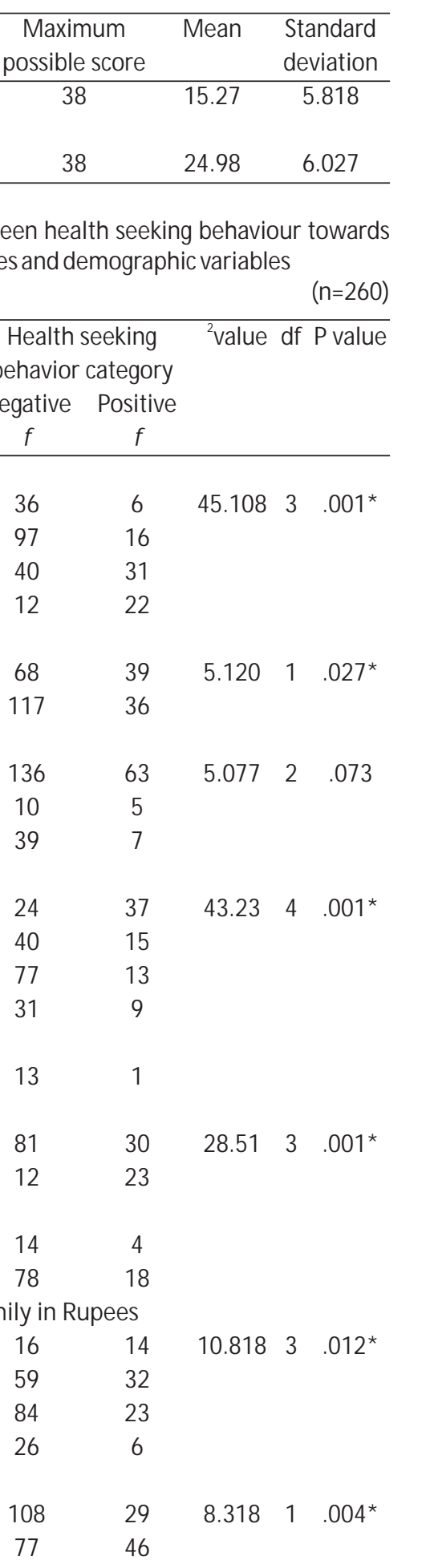

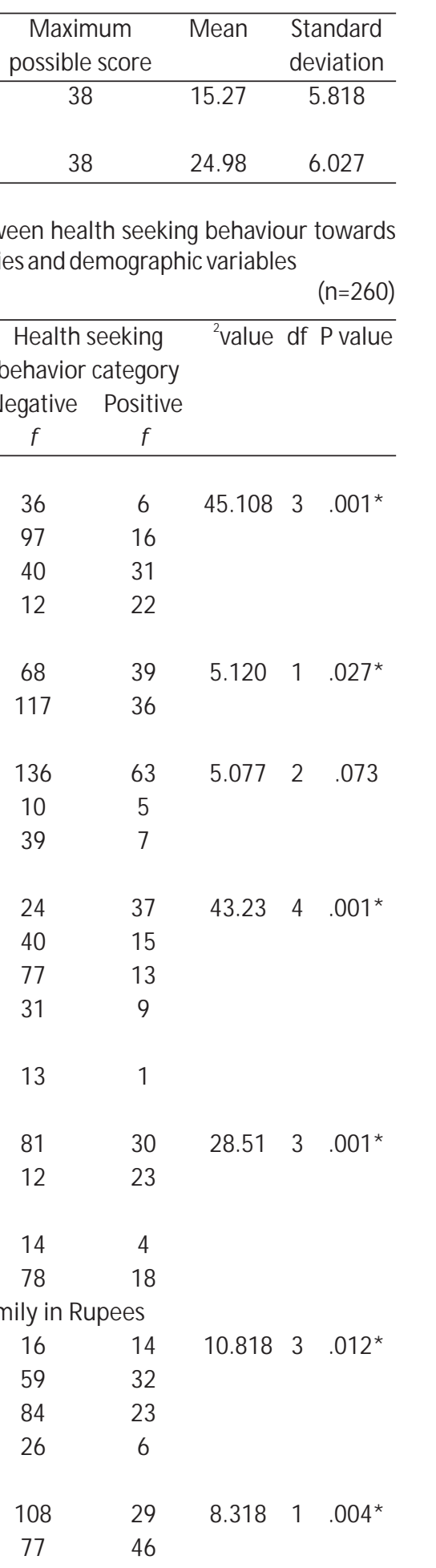

$5.120 \quad 1 \quad .027^{*}$

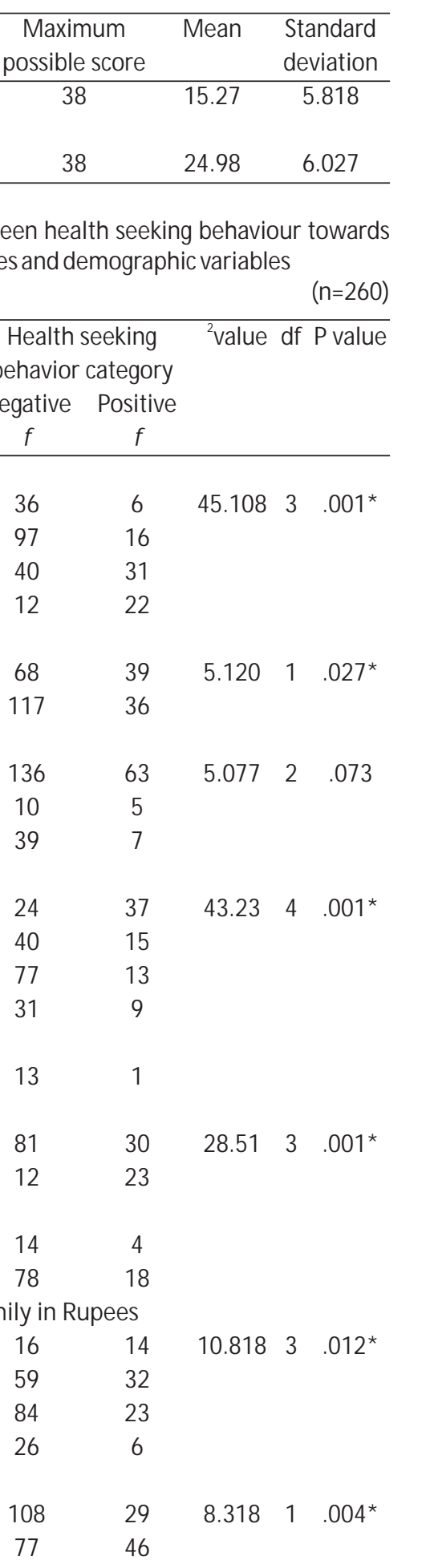

$5.077 \quad 2 \quad .073$

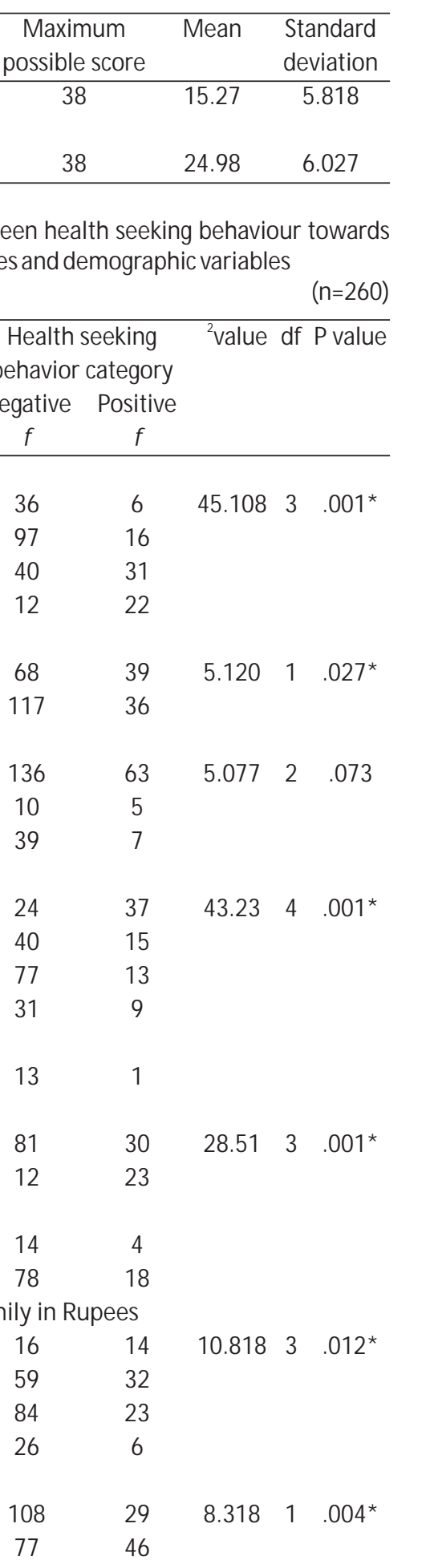

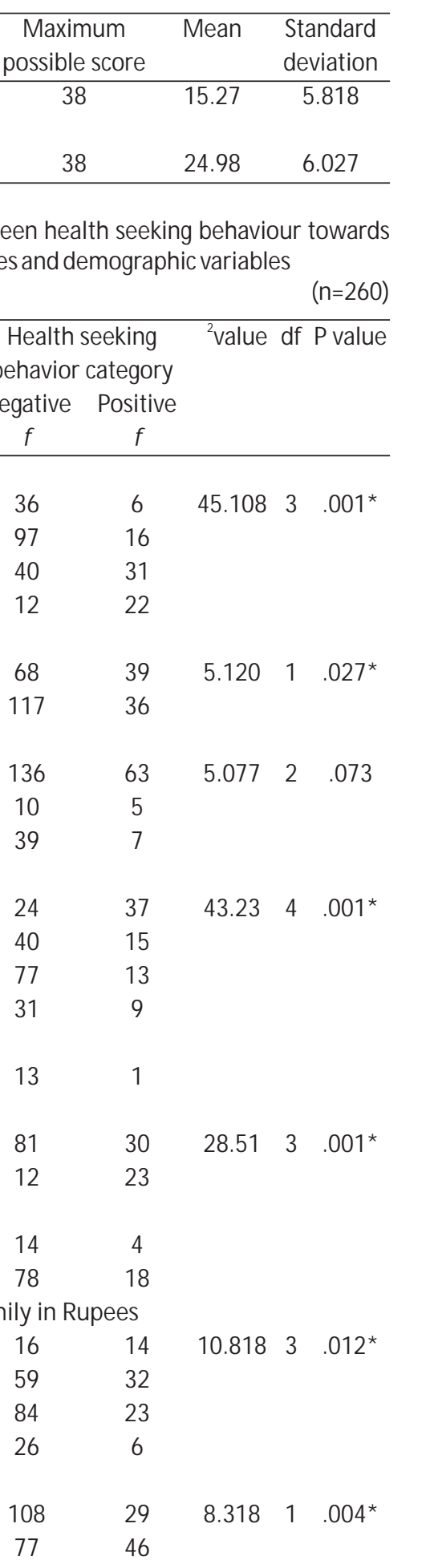

$43.23 \quad 4 \quad .001^{*}$

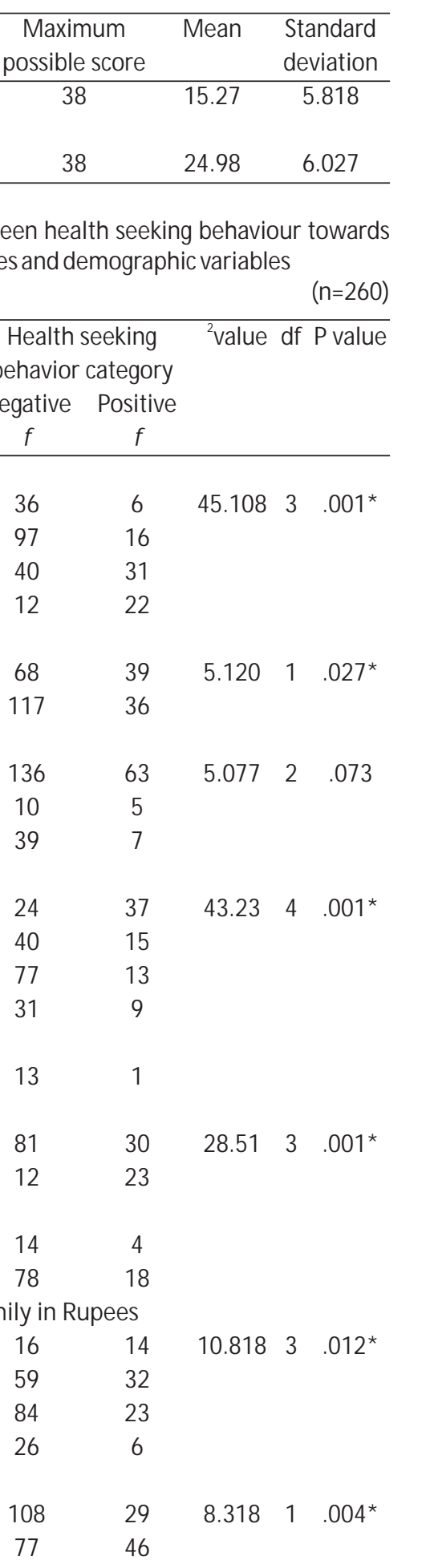

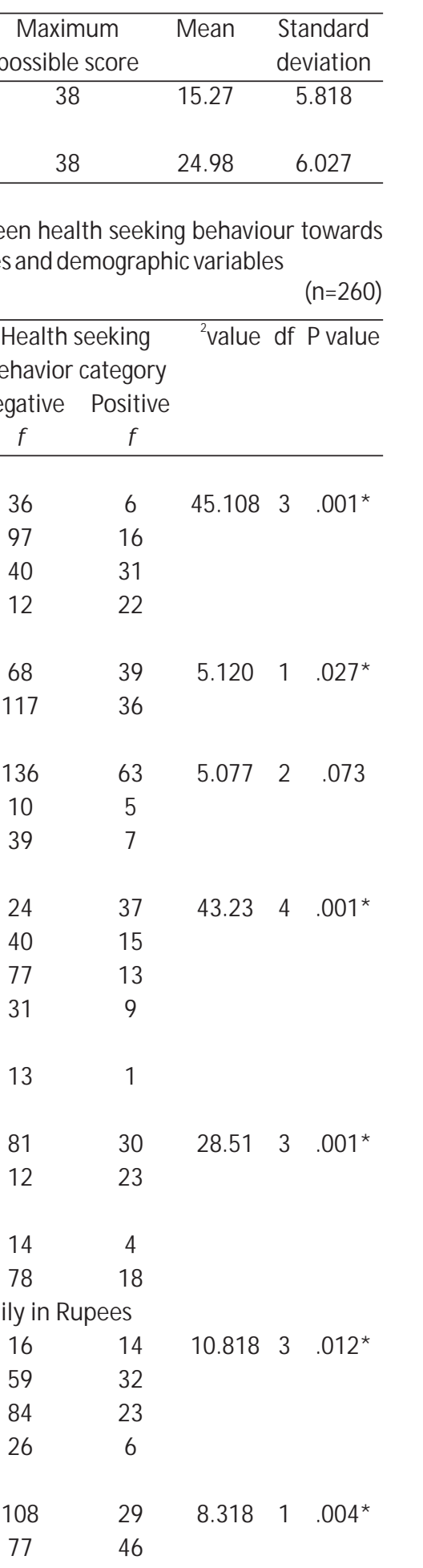

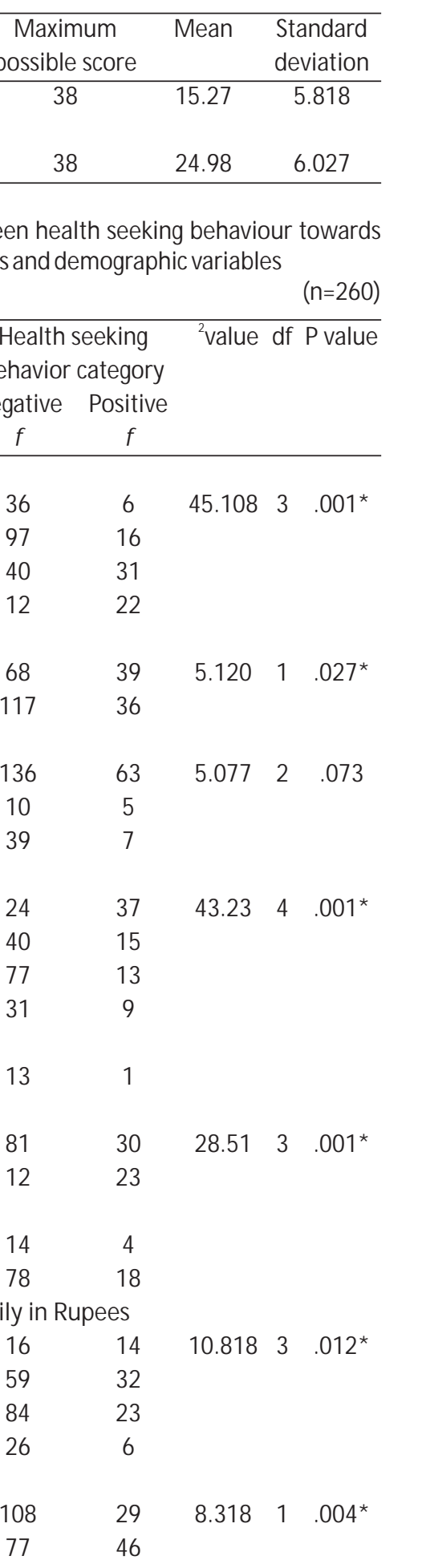

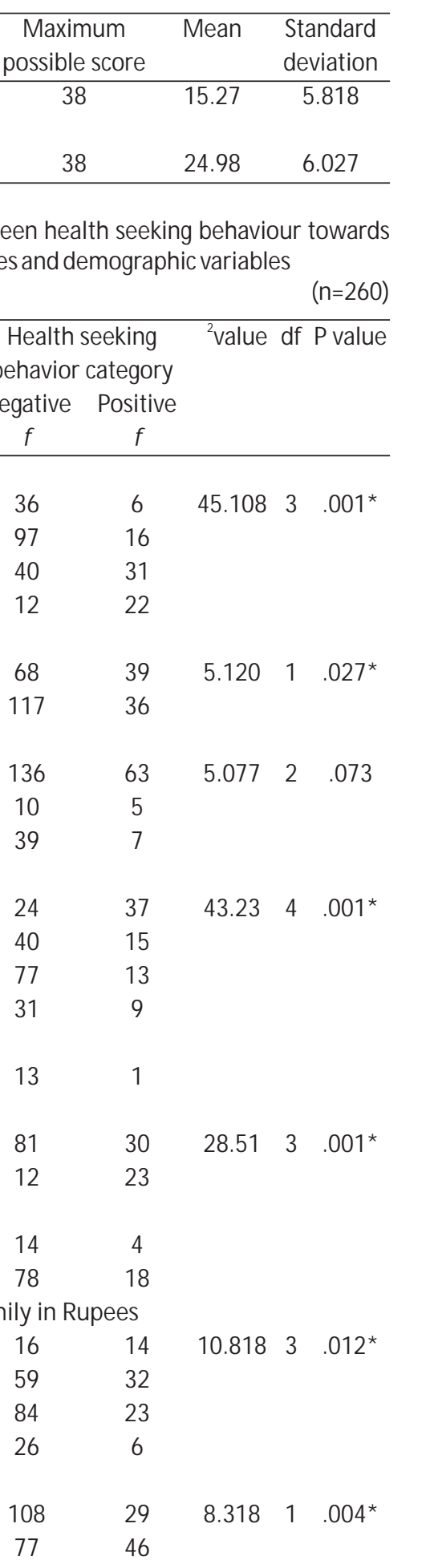

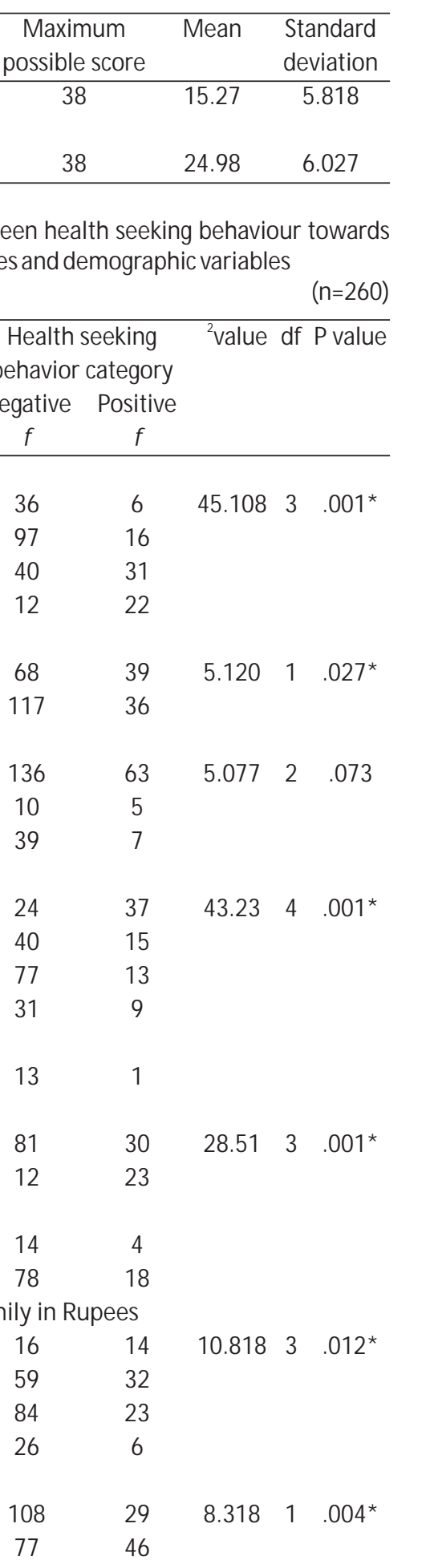

$28.513 .001^{*}$

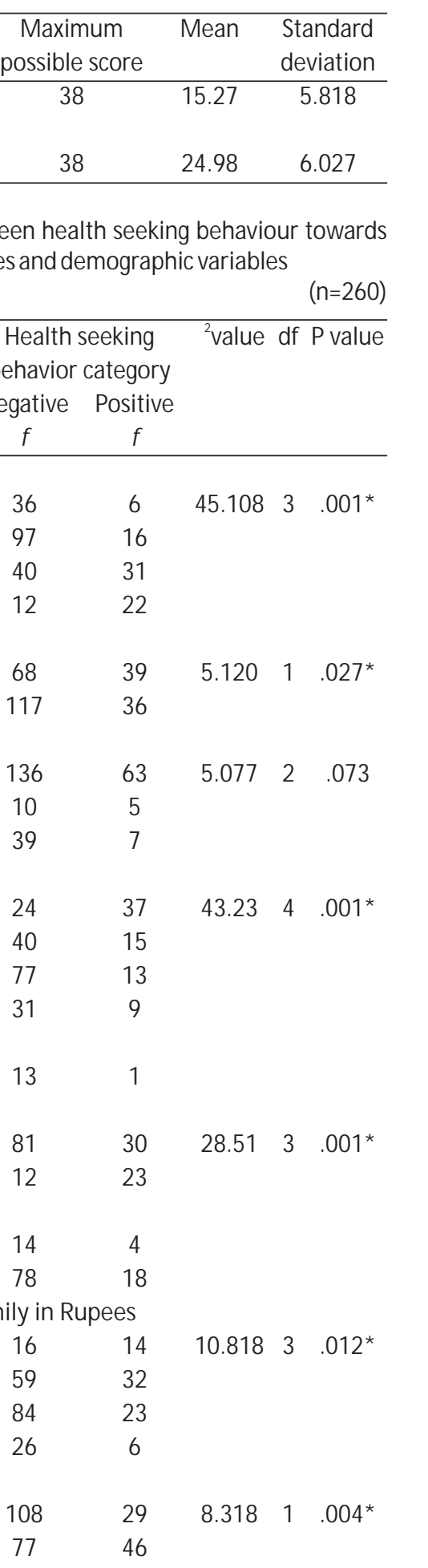

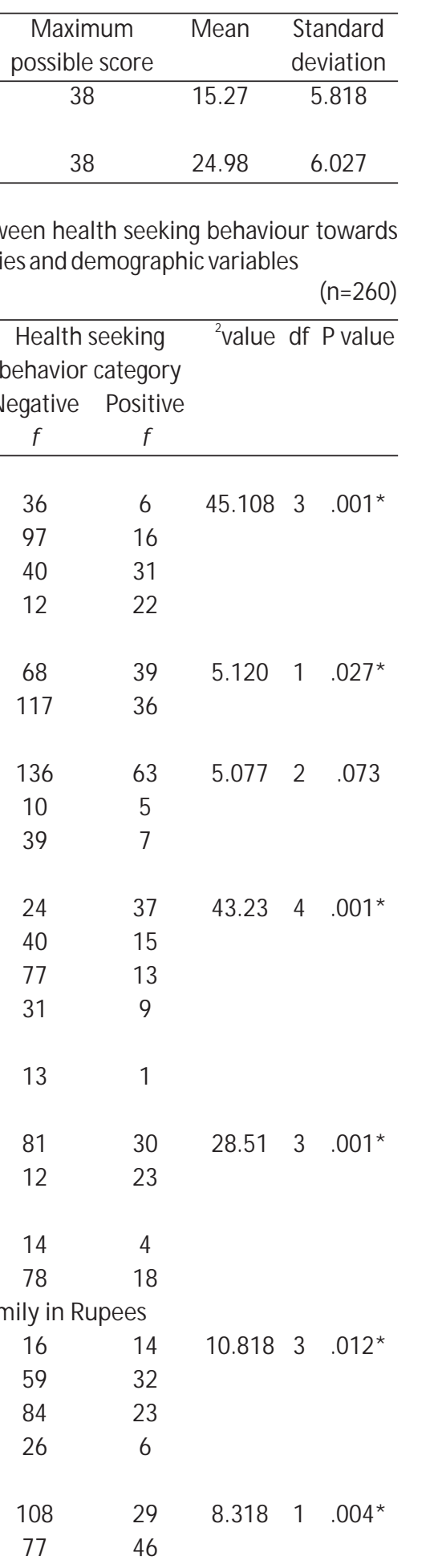

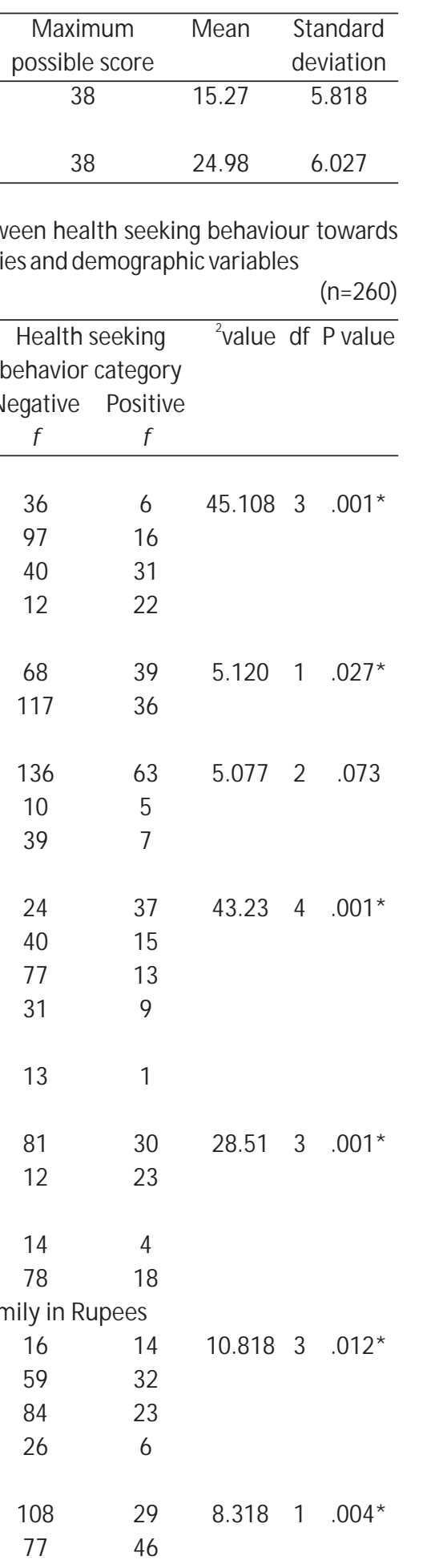

$8.3181 .004^{*}$

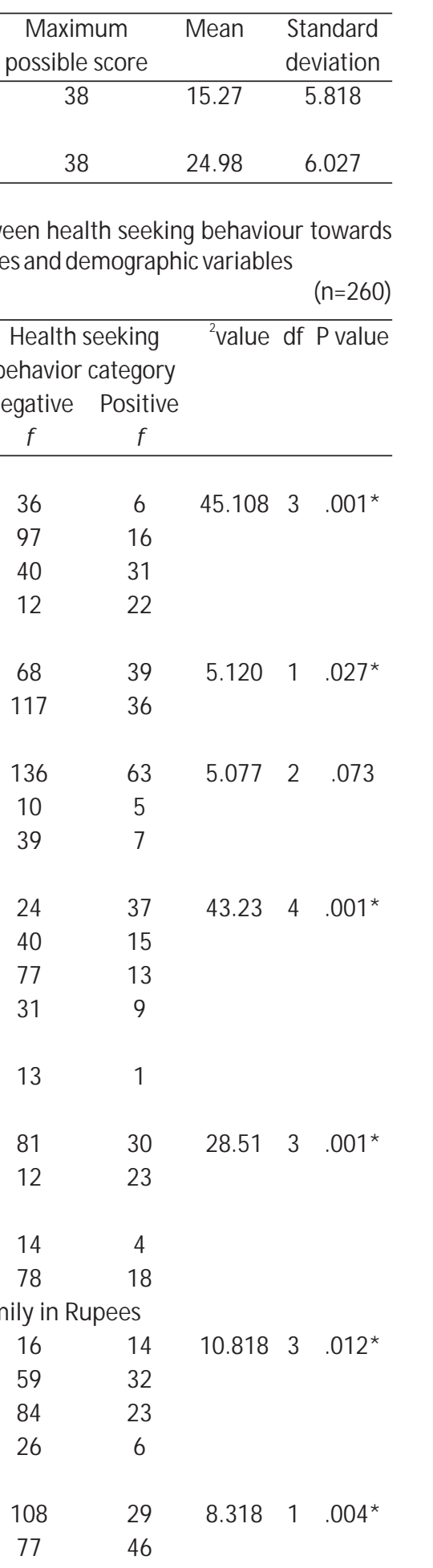

$10.818 \quad 3 \quad .012^{*}$ 
Table 4: Association between health seeking behaviour towards private health facilities and demographic variables $(n=260)$

\begin{tabular}{|c|c|c|c|c|c|}
\hline \multirow[t]{2}{*}{$\begin{array}{l}\text { Sample } \\
\text { characteristics }\end{array}$} & \multicolumn{2}{|c|}{$\begin{array}{c}\text { Health seeking } \\
\text { behavior category }\end{array}$} & \multirow[t]{2}{*}{$\chi^{2}$ value } & \multirow[t]{2}{*}{$\mathrm{df}$} & \multirow[t]{2}{*}{$P$ value } \\
\hline & $\begin{array}{c}\text { Negative } \\
f\end{array}$ & $\begin{array}{c}\text { Positive } \\
\mathrm{f}\end{array}$ & & & \\
\hline \multicolumn{6}{|l|}{ 1. Age in years } \\
\hline $20-30$ & 0 & 42 & 17.527 & 3 & $.001 *$ \\
\hline $31-40$ & 11 & 102 & & & \\
\hline $41-50$ & 18 & 53 & & & \\
\hline $51-60$ & 7 & 27 & & & \\
\hline \multicolumn{6}{|l|}{ 2. Gender } \\
\hline Male & 13 & 94 & 0.439 & 1 & .586 \\
\hline Female & 23 & 130 & & & \\
\hline \multicolumn{6}{|l|}{ 3. Religion } \\
\hline Hindu & 29 & 170 & 2.571 & 2 & .304 \\
\hline Christian & 0 & 15 & & & \\
\hline Muslim & 7 & 39 & & & \\
\hline \multicolumn{6}{|l|}{ 4. Education } \\
\hline Primary & 22 & 39 & 36.761 & 4 & $.001^{*}$ \\
\hline Secondary & 7 & 48 & & & \\
\hline Higher secondary & 7 & 83 & & & \\
\hline Graduate & 0 & 40 & & & \\
\hline $\begin{array}{l}\text { Post graduate } \\
\text { and above }\end{array}$ & 0 & 14 & & & \\
\hline \multicolumn{6}{|l|}{ 5. Occupation } \\
\hline Unemployed & 21 & 90 & 6.284 & 3 & .097 \\
\hline Cooli worker & 5 & 29 & & & \\
\hline Government & & & & & \\
\hline employee & 2 & 16 & & & \\
\hline Private job & 7 & 89 & & & \\
\hline \multicolumn{6}{|c|}{ 6. Monthly income of family } \\
\hline$<5000$ & 1 & 29 & 9.013 & 3 & $.028 *$ \\
\hline $5000-10000$ & 20 & 71 & & & \\
\hline $10001-25000$ & 11 & 96 & & & \\
\hline$>25000$ & 4 & 28 & & & \\
\hline \multicolumn{6}{|l|}{ 7. Type of family } \\
\hline Nuclear & 12 & 125 & 6.282 & 1 & $.018 *$ \\
\hline Joint & 24 & 99 & & & \\
\hline \multicolumn{6}{|l|}{ 8. House hold size } \\
\hline $1-5$ & 17 & 144 & 3.999 & 2 & .127 \\
\hline $6-10$ & 15 & 66 & & & \\
\hline$>10$ & 4 & 14 & & & \\
\hline
\end{tabular}

*Significant

to be changed as to attract them more to government hospitals and health centers. It can be done through improving the quality of care, proper maintenance of facilities and also by inculcating a caring and sympathetic attitude in health professionals while dealing the patients.

\section{Acknowledgment :}

I express my heartfelt gratitude to my guide Mr. Y. N. Shashidhara, Associate Professor and In charge Head, Department of Community Health Nursing, Manipal, my co-guide M rs. M alathi G Nayak, Assistant Professor, Dept. of Community Health Nursing, Manipal and Dr. Anice George, Dean, M anipal College of Nursing, Manipal, for the great support I got throughout my study.

\section{References:}

1. Census of India. Available from http://www.censusindia.gov.in/. Date of accession of the site $2012 \mathrm{M}$ arch.

2. Keith Tones. Health Promotion, Health Education and the Public Health. Oxford Textbook of Public Health. Oxford University Press; 2004. 829-863.

3. United States Agency for International Development Health Policy Initiative. Report on Health seeking behavior in rural Uttar Pradesh Available from pdf.usaid.gov/pdf_docs/PNADR389.pdf. date of accession M arch 2012

4. Lakhwinder P Singh. Shiv D Gupta. Health Seeking Behaviour and Healthcare Services in Rajasthan, India: A Tribal Community's Perspective. Institute of Health M anagement Research-Jaipur; 1996: IIHMR Working Paper No. 1. Available from jaipur.iihmr.org/ Publications/Workingp/1.pdf

5. Muhammad Umair Mushtaq, Sibgha Gull, Mushtaq Ahmad Shad, Javed Akram. Socio-demographic correlates of the health-seeking behaviours in two districts of Pakistan's Punjab province. J Pak M ed Assoc. 2011; 61: 1205-1209. Available from http://jpma.org.pk/full article_text.php?article_id $=3188$ 